\title{
Vertical Drop Test and Simulation of a Fokker F-28 Fuselage Section
}

\author{
K. E. Jackson ${ }^{1}$ J. D. Littell ${ }^{2}$ M. S. Annett ${ }^{3}$ and I. M. Haskin ${ }^{4}$ \\ ${ }^{1}$ NASA Langley Research Center, Research Directorate, Structural Dynamics Branch, \\ Mail Stop 495, 14 West Bush Road, Hampton, VA 23681; PH (757) 864-4147; FAX \\ (757) 864-8547; email: Karen.E.Jackson-1 @ nasa.gov \\ ${ }^{2}$ NASA Langley Research Center, Research Directorate, Structural Dynamics Branch, \\ Mail Stop 495, 14 West Bush Road, Hampton, VA 23681; PH (757) 864-4195; FAX \\ (757) 864-8547; email: Justin.D.Littell@ nasa.gov \\ ${ }^{3}$ NASA Langley Research Center, Research Directorate, Structural Dynamics Branch, \\ Mail Stop 495, 14 West Bush Road, Hampton, VA 23681; PH (757) 864-4149; FAX \\ (757) 864-8547; email: Martin.S.Annett@nasa.gov \\ ${ }^{4}$ NASA Glenn Research Center, Structural Mechanics Branch, Mail Stop 152, 21000 \\ Brookpark Road, Cleveland, OH 44135; PH (216) 433-2119; FAX (216) 433-8000; \\ email: Ian.M.Haskin@nasa.gov
}

\begin{abstract}
In March 2017, a vertical drop test of a 3.048-m (10-ft) section of a Fokker F-28 aircraft was conducted as a part of a joint NASA/FAA effort to investigate the performance of transport aircraft under realistic crash conditions. The section was configured with two rows of aircraft seats, in a triple-double configuration. A total of ten Anthropomorphic Test Devices (ATDs) were secured in the seats using standard seat belt restraints. The section was also configured with luggage in the cargo hold. Two hat racks were added, each with mass loading of $37.2-\mathrm{kg}$ per linear meter $(25-\mathrm{lb} / \mathrm{ft})$. The drop test was performed at the Landing and Impact Research facility located at NASA Langley Research Center in Hampton, Virginia. The planned impact velocity was $9.144-\mathrm{m} / \mathrm{s}$ (360-in/s) onto soil. A second objective was to assess the capabilities of finite element simulations to predict the test response. A finite element model was developed for execution in LS-DYNA ${ }^{\circledR}$, a commercial explicit nonlinear transient dynamic code. The model contained accurate representations of the airframe structure, the hat racks and hat rack masses, the floor and seat tracks, and the luggage in the cargo hold. Concentrated masses were used to represent the inertial properties of the seats, restraints, and ATD occupants. The model was executed to generate analytical predictions of airframe responses, which were compared with test data to validate the model.
\end{abstract}

\section{INTRODUCTION}

Recently, the topic of the crashworthy behavior of transport aircraft has become a subject of significant research by the Federal Aviation Administration (FAA) and the National Aeronautics and Space Administration (NASA). In 2015, the FAA created an Aviation Rulemaking Advisory Committee (ARAC) whose goal is to generate recommendations for establishing whole airframe crashworthiness and ditching requirements for transport aircraft, Federal Register (2015). To support this effort, 
NASA and the FAA signed an interagency research agreement in 2016 which enabled the vertical drop test of a 3.048-m-long (10-ft) section of a Fokker F-28 Fellowship aircraft. The portion of the airframe from which the section was taken is shown in Figure 1 and a pre-test photograph of the section is shown in Figure 2.

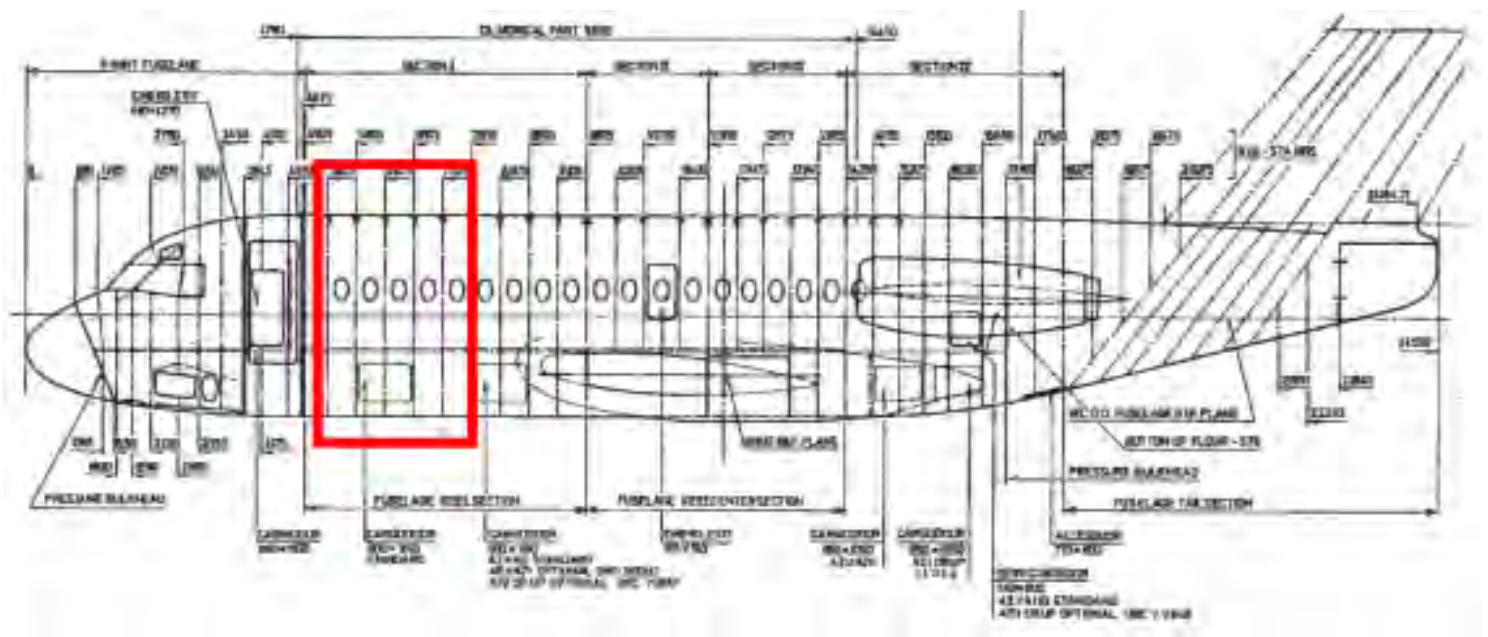

Figure 1. Side-view schematic of the F-28 aircraft highlighting the location of the 3.048-m-long fuselage section.

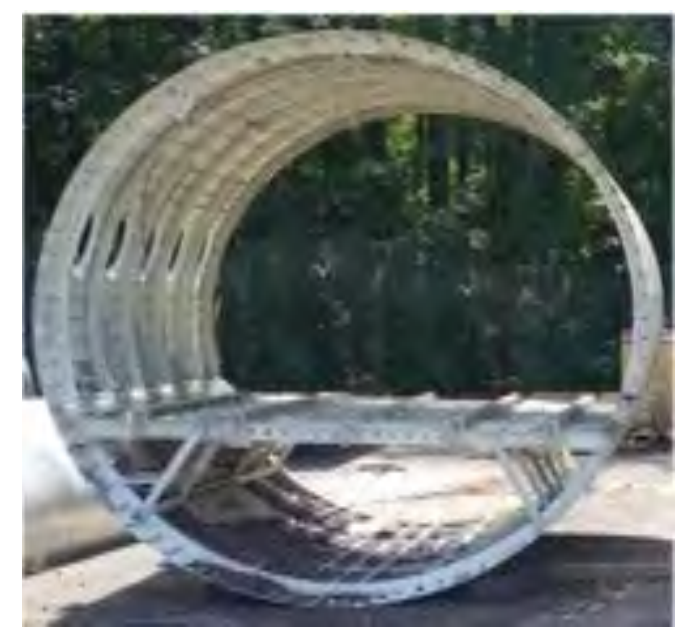

Figure 2. Photograph of the F-28 fuselage section.

The Fokker F-28 Fellowship is a short range jet airliner, sometimes referred to as a regional jet, that is designed and built by Dutch aircraft manufacturer Fokker. It was originally intended to haul 50 passengers over approximately 1,609 km (1,000 miles), but was later reconfigured to hold 60-65 passengers. In the late 1990's, NASA Langley obtained one complete aircraft, which had been retired from service, plus three fuselage sections, for testing under the Systems Approach to Crashworthiness Program, Jones (2002). In 2001, a vertical drop test of the first F-28 fuselage section was performed, Lyle (2007) and Stockwell (2003). This section was tested at an impact velocity of $9.2-\mathrm{m} / \mathrm{s}(30.2-\mathrm{ft} / \mathrm{s})$ and was loaded with twenty $34.02-\mathrm{kg}(75-\mathrm{lb})$ lead masses, attached to the seat rails, ten per side. The section was not loaded with luggage in the cargo hold and, consequently, exhibited discrete failures at the bottom centerline and at two 
symmetric locations on either side of the bottom centerline. The floor also buckled and failed along the centerline.

In March 2017, a vertical drop test of a 3.048-m-long (10-ft) forward section of a Fokker F-28 Fellowship aircraft was conducted as a part of a joint NASA/FAA effort to investigate the performance of transport category aircraft under realistic crash conditions. A photograph of the fuselage section is shown in Figure 3(a). Prior to the drop test, the section was configured with two rows of aircraft seats, in a triple-double configuration, as depicted in Figure 3(b). A total of ten Anthropomorphic Test Devices (ATDs) were secured in the seats using standard seat belt restraints. The section was also configured with luggage in the cargo hold and two hat racks, each with mass loading of $37.2-\mathrm{kg}$ per linear meter $(25-\mathrm{lb} / \mathrm{ft})$. The drop test was conducted at the Landing and Impact Research (LandIR) facility located at NASA Langley Research Center. The planned impact velocity was $9.144-\mathrm{m} / \mathrm{s}(360-\mathrm{in} / \mathrm{s})$ onto a $0.61-\mathrm{m}(2-\mathrm{ft})$ high soil bed.

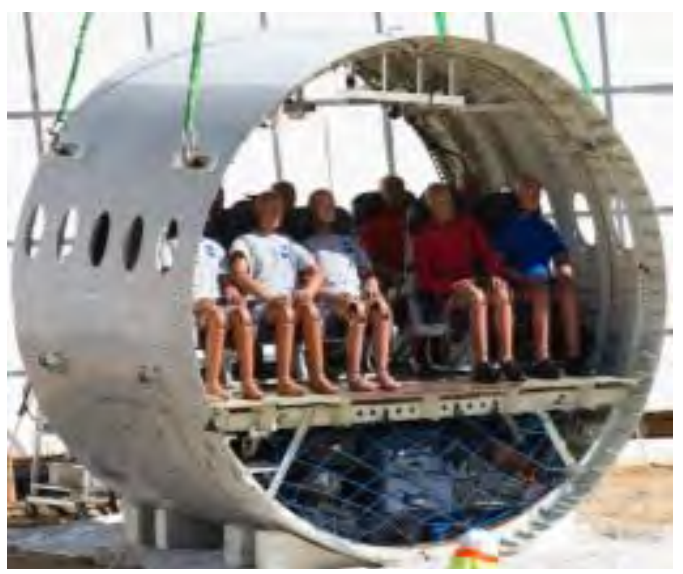

(a)Pre-test photo of the test article.

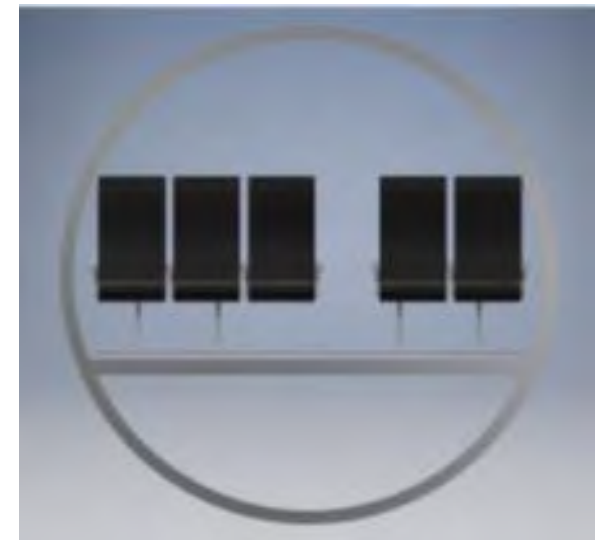

(b)The $3+2$ seat arrangement.

Figure 3. Photograph of the F-28 section and a schematic of the $3+2$ seat configuration.

A second objective of the NASA/FAA collaborative effort was to assess the capabilities of analytical methods to predict the test response. A finite element model was developed of the F-28 fuselage section for execution in LS-DYNA ${ }^{\circledR}$ [Hallquist (March 2006), Hallquist (August 2006), Hallquist (August 2006)], which is a commercial code for simulating explicit nonlinear transient dynamic models. The model is shown in Figure 4 and contained accurate representations of the airframe structure, the hat racks and hat rack masses, the floor and seat tracks, and the luggage in the cargo hold. Concentrated masses were used to represent the inertial properties of the seats, restraints, and ATD occupants.

The following sections of the paper will provide additional information regarding the test set-up, model development, and test-analysis comparisons of time-history responses and structural deformations. 


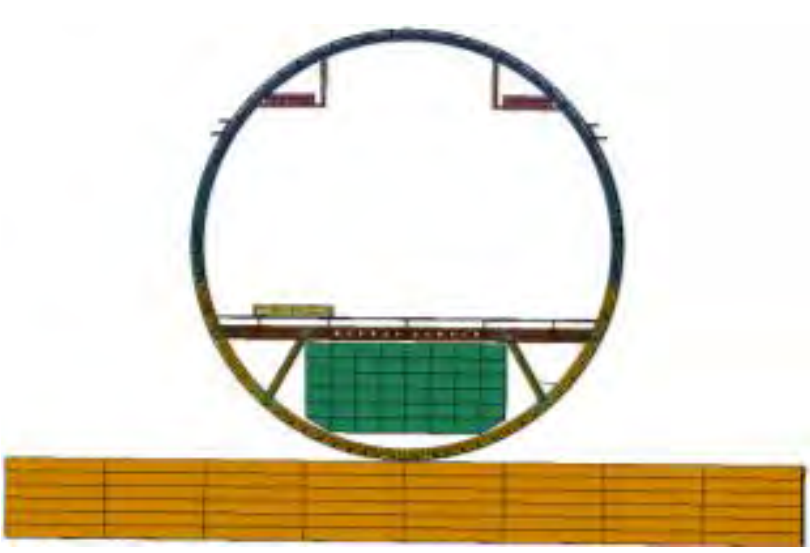

(a)Front view of model.

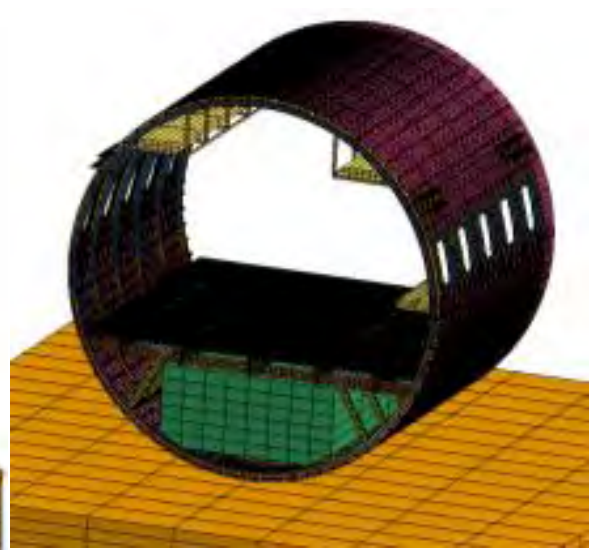

(b)Three-quarter view of model.

Figure 4. Views of the finite element model of the F-28 fuselage section.

\section{TEST SET-UP}

The vertical drop test of the F-28 forward section was performed by raising the test article approximately 4.267-m (14-ft) in the air and releasing it to impact a soil bed. The measured impact velocity was $8.839-\mathrm{m} / \mathrm{s}(29-\mathrm{ft} / \mathrm{s})$. Prior to the test, one side of the fuselage section was painted white and 1.27 -cm-diameter $(0.5$-in.) black dots were painted on the white surface in a random pattern. The painted dots were used as targets, which were tracked using three-dimensional photogrammetry, Littell (2010), Littell (2016), and Littell (2017).

The forward barrel section consists of five windows and six frames between Fuselage Stations (FS) FS 5305 and FS 7805. All of the interior paneling, along with the floor was removed. A cargo door is located on the lower left side of the section. The barrel section is approximately $2.74-\mathrm{m}(9-\mathrm{ft})$ in length and $2.74-\mathrm{m}(9-\mathrm{ft})$ wide at the floor. The standard seat configuration for this aircraft was used, which included 2 rows of seats in a triple-double $(3+2)$ configuration, which can accommodate up to 10 ATDs. Luggage was loaded into the cargo hold of the section and was restrained by netting on both the forward and aft ends. Overhead bins were simulated by attaching plates and ballasting weight of up to $37.2-\mathrm{kg}$ per linear meter $(25-\mathrm{lb} / \mathrm{ft})$ at the bin attachment points on the frames. Floor panels were installed and cut to fit the section length, as needed. The floor was ballasted using a combination of seated ATDs, data systems, and lead weights to achieve a loading condition of $669.67-\mathrm{kg} / \mathrm{m}$ (450-lb/linear foot). Loading conditions are dictated in the F-28 weight and balance manual. The pre-test fully loaded F-28 fuselage section weighed $2,025.3-\mathrm{kg}(4,465-\mathrm{lb})$ and is shown in Figure 3(a).

The impact surface was a 4.57-m wide, 6.1-m long, and 0.61-m high (15-ft wide, 20-ft long, 2-ft high) soil bed. The soil was a mixture of sand and clay. Soil characterization tests were performed after the F-28 fuselage section impact test and prior to removal of the test article. Ball penetrometer and drop cone penetrometer tests were performed at three locations. In addition, soil samples were taken at three locations. The measured average density of the soil was $2,165.7-\mathrm{kg} / \mathrm{m}^{3}\left(0.07824-\mathrm{lb}_{\mathrm{in}}{ }^{3}\right)$ with an 
average moisture content of $11.4 \%$. Based on the soil characterization tests, the sand/clay mixture is classified as a firm soil.

The F-28 fuselage section was instrumented to collect a total of 145 channels of data at 10,000 samples per second per channel. The majority of the instrumentation was mounted in the onboard ATDs. Approximately 35 channels were located on the airframe structure. Some of these channel positions are shown in Figure 5. Since the test/analysis comparisons are focused on structural responses, the seat track channels will be highlighted.

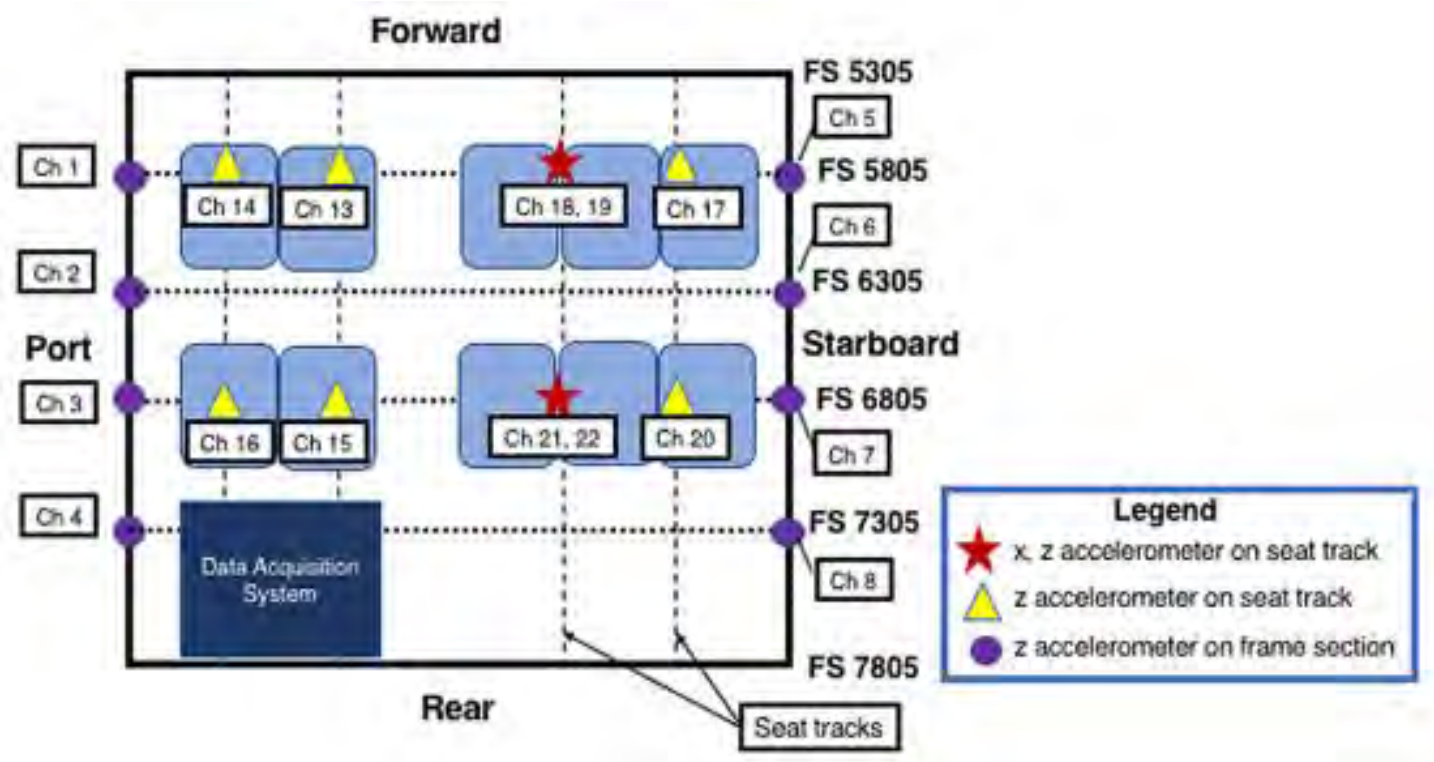

Figure 5. Instrumentation layout on the F-28 floor.

\section{MODEL DEVELOPMENT}

The LS-DYNA model, shown in Figure 4, was created from a NASTRAN model of the F-28 Fellowship aircraft that was provided to NASA by Fokker at the time of original purchase of the airframe hardware. The total weight of the structural model (minus the soil) is 1,955.3-kg (4,310.7-lb), which includes 418.6-kg (922.8-lb) of luggage; $927.14-\mathrm{kg}(2,044-\mathrm{lb})$ of floor loading; 56.7-kg (125-lb) of hat rack mass; 77.1$\mathrm{kg}$ (170-lb) for the Data Acquisition System (DAS) box; and 475.8-kg (1,048.9-lb) for the fuselage empty weight. The measured weight of the fully loaded F-28 fuselage section is $2025.3-\mathrm{kg}(4,465-\mathrm{lb})$. Thus, the model is approximately $68-\mathrm{kg}(150-\mathrm{lb})$ too light. The model contained: 114,636 shell elements; 48,716 solid elements; 141,080 nodes; 36 parts; 10 materials; 1 contact definition; 1 initial velocity card; and, 1 Single Point Constraint (SPC) boundary condition that was used to fix the side and bottom nodes of the soil.

Most of the material models were converted directly from the NASTRAN model to represent aluminum components using an elastic-plastic material model in LS-DYNA. The floor panels were constructed of two different materials: aluminum-clad balsa wood, or fiberglass covered Nomex honeycomb. Since no material properties were 
available for the floor panels, test specimens were obtained and three-point flexure tests were conducted and simulated to obtain accurate material properties for these parts, as shown in Figure 6. The soil was represented using *MAT_SOIL_AND_FOAM in LSDYNA with properties of hard soil. Finally, the luggage was represented using solid elements that were assigned material properties obtained from a quasi-static crush test of stacked luggage, as described in Jackson (2002).

The nodes forming the fuselage section were assigned an initial velocity of $8.839-\mathrm{m} / \mathrm{s}$ (348-in/s) in the downward vertical direction, matching the measured velocity. An automatic contact was defined that prevents any node from penetrating any surface. Also, the inertial properties of the seats, occupants, and restraint systems were represented using concentrated masses, placed on the floor at the approximate locations of seat attachment points. The model was executed for an end time of 0.2-s and required 135 hours of execution time running LS-DYNA Version 971 double precision, on 8 processors of a workstation computer. Output requests included time history responses corresponding to accelerometer locations and structural deformations.

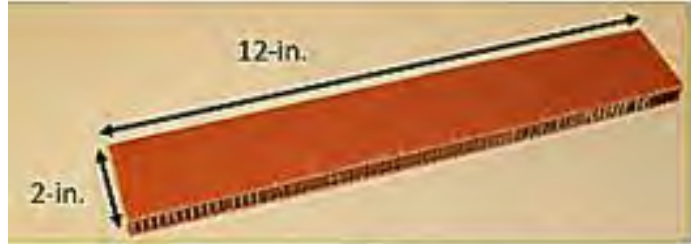

Three-point bend floor specimen (Nomex honeycomb with fiberglass face sheets)

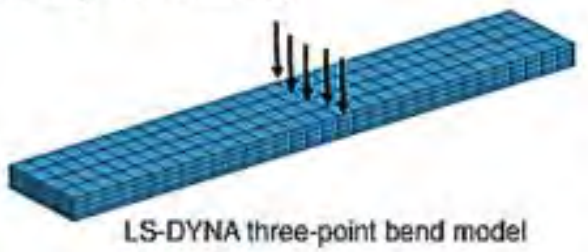

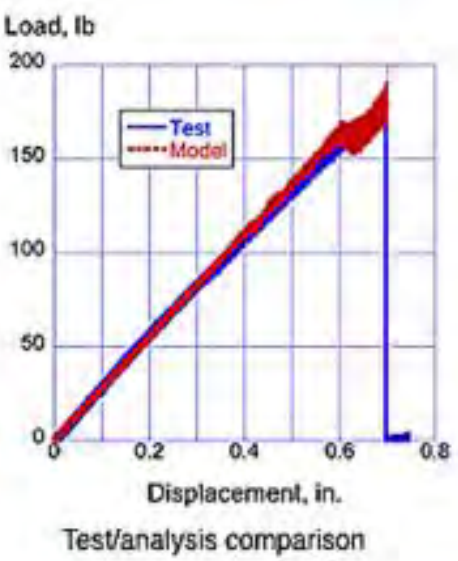

Testanalysis comparison

Figure 6. Three-point bend testing and simulation of floor panels.

\section{TEST/ANALYSIS COMPARISONS}

The acceleration and velocity time history responses of the test data and analytical predictions are compared, as well as airframe deformations and failures, in this section of the paper.

\section{Acceleration and Velocity Time History Comparisons}

Test data were reduced following the drop test, according to the procedures outlined in Fasanella (2002) and this analysis indicated that several channels were over-ranged, including Channels 18 and 19 (see Figure 5). Consequently, test/analysis comparisons for these channels are not shown. Please note that the experimental and analytical acceleration responses were both filtered using a Society of Automotive Engineering (SAE, 1995) Channel Filter Class (CFC) 60-Hz low-pass filter. Also note that the test velocities were obtained by integration of the raw test acceleration data. For the model, 
velocity data were output directly from the simulation. The test/analysis comparisons of acceleration and velocity responses are shown in Figures 7 (a) and (b), respectively, for the port window location at FS 5805 (see Figure 5). At this location, the model exhibits four acceleration peaks, the first two peaks are higher in magnitude than the test. However, the overall pulse durations are similar. It is also interesting to note that, even after filtering using an SAE CFC 60-Hz filter, the test signal still contains many oscillations. The velocity responses at this location, shown in Figure 7(b), indicate that both the test and predicted curves agree well during the initial portion of the pulse, up to approximately 0.015 -s. After this time, the predicted response removes velocity more quickly than the test and crosses zero velocity slightly before the test response.

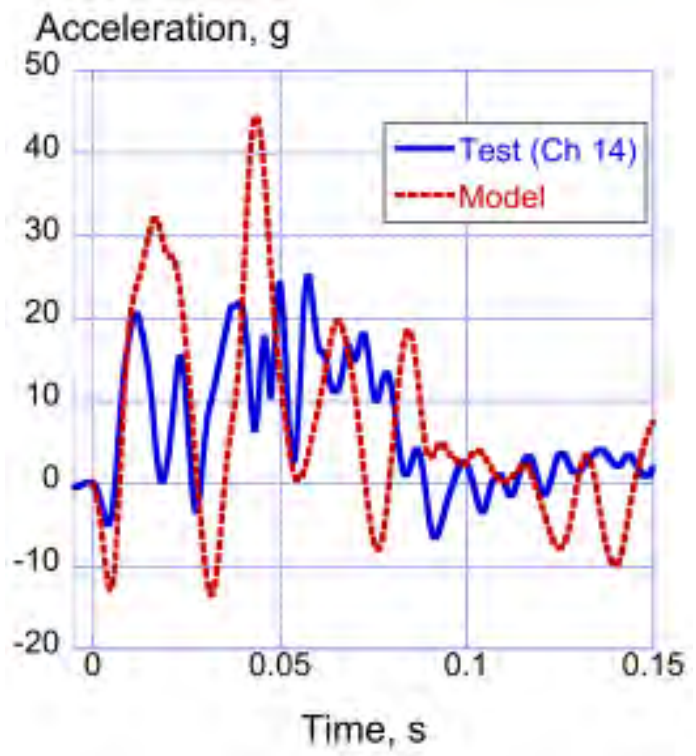

(a)Acceleration responses.

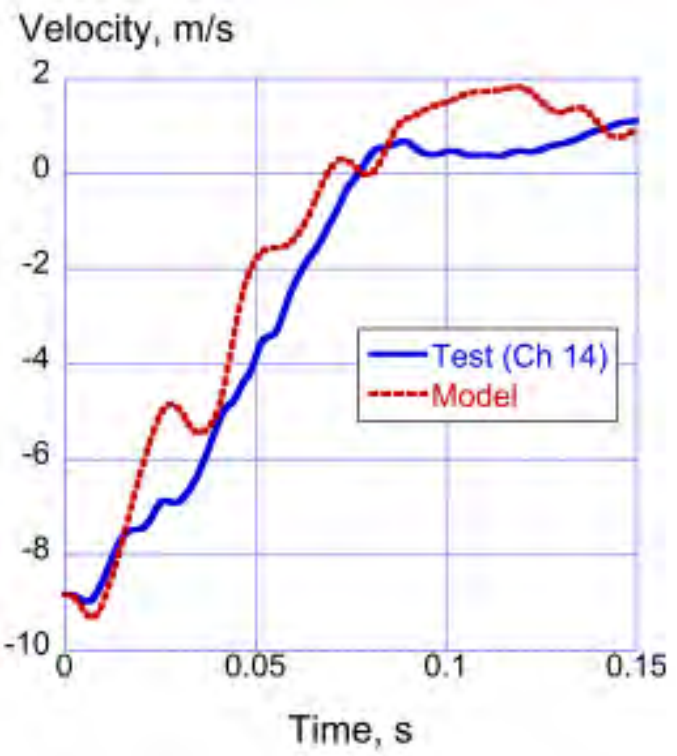

(b) Velocity responses.

Figure 7. Acceleration and velocity comparisons at the port window at FS 5805.

The test/analysis comparisons of acceleration and velocity responses are shown in Figures 8 (a) and (b), respectively, for the port aisle location at FS 5805 (see Figure 5). The test and model acceleration time histories both indicate an initial negative peak of 25-g. Subsequently, the model exhibits two peaks of 50- and 30-g, but generally matches the test response following the first large peak. The velocity responses agree well, crossing zero velocity at approximately the same time and exhibiting similar rebound responses.

The test/analysis comparisons of acceleration and velocity responses are shown in Figures 9 (a) and (b), respectively, for the starboard window location at FS 5805 (see Figure 5). The test and model acceleration time histories agree very well, especially during the early part of the pulse. The simulation matches the magnitude and phase of the test oscillations well, up to 0.075 -s. After 0.075 -s, the model over predicts the test acceleration responses. The velocity responses agree very well, again up to 0.075 -s. After this time, the two curves deviate and the model curve crosses zero velocity earlier than the test. 


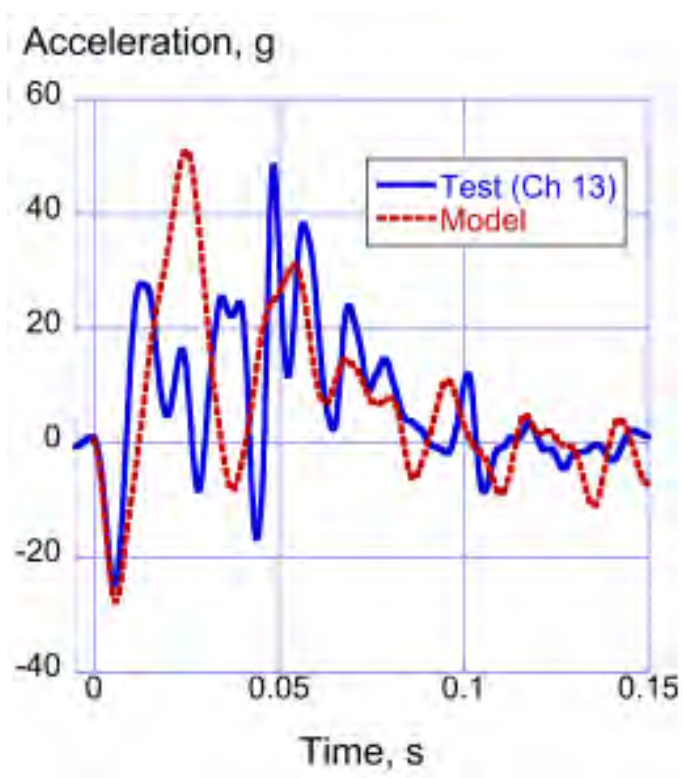

(a)Acceleration responses.

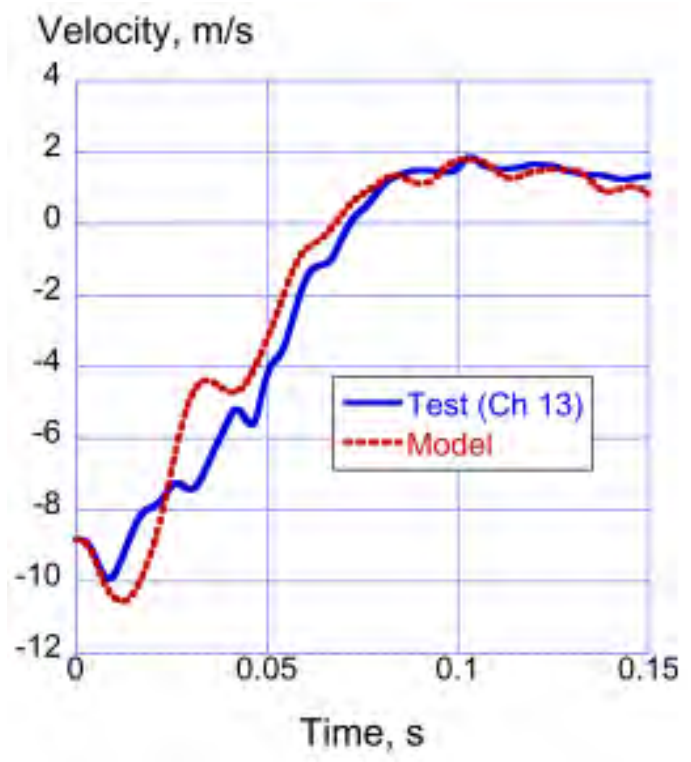

(b) Velocity responses.

Figure 8. Acceleration and velocity comparisons at the port aisle at FS 5805.

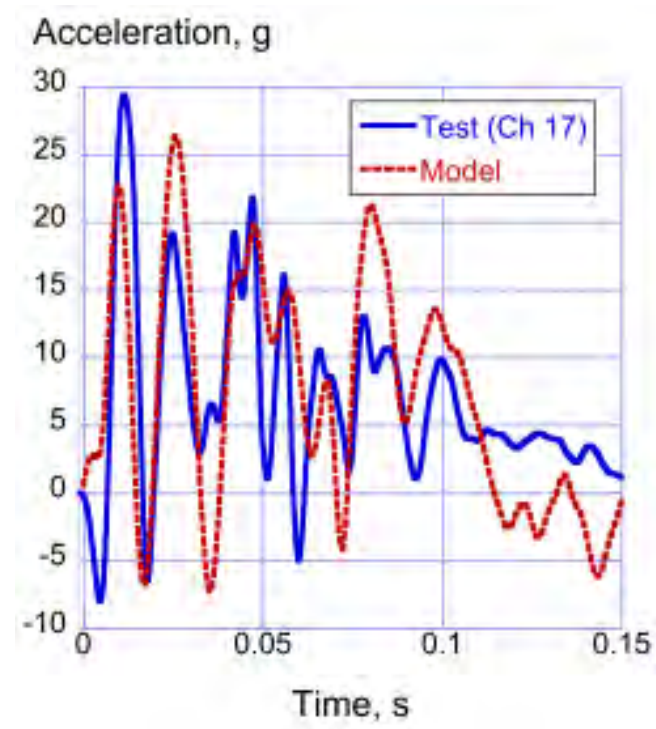

(a)Acceleration responses.

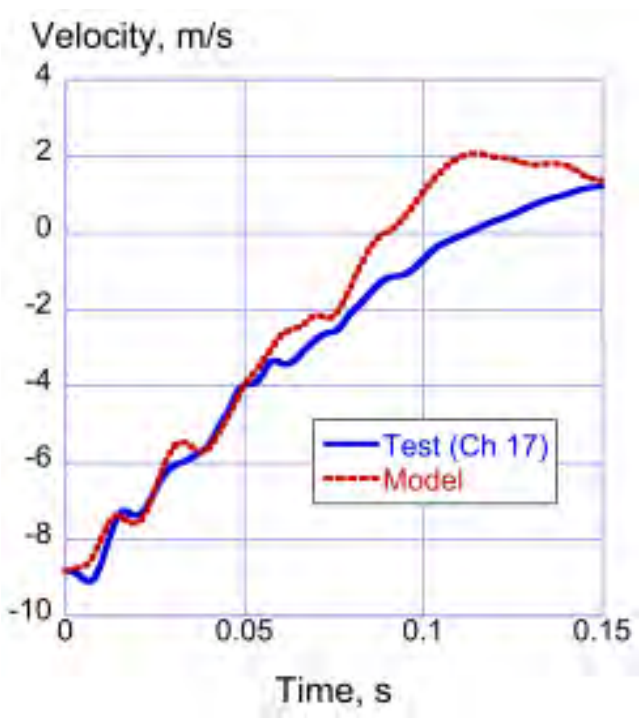

(b) Velocity responses.

Figure 9. Acceleration and velocity comparisons at the starboard window at FS 5805.

The test/analysis comparisons of acceleration and velocity responses are shown in Figures 10 (a) and (b), respectively, for the port window location at FS 6805 (see Figure 5). The model acceleration response again exhibits four peaks and matches the duration of the test response exactly. The test acceleration response contains many oscillations, making it difficult to discern a definitive pulse shape. The test and model velocity responses agree well, even crossing zero at the same time, though the rebound velocity responses are different between test and model. 


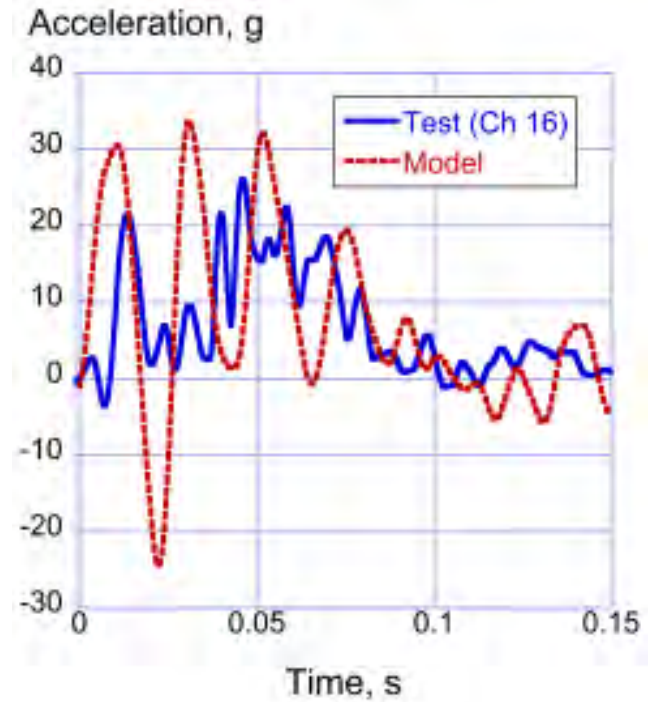

(a) Acceleration responses.

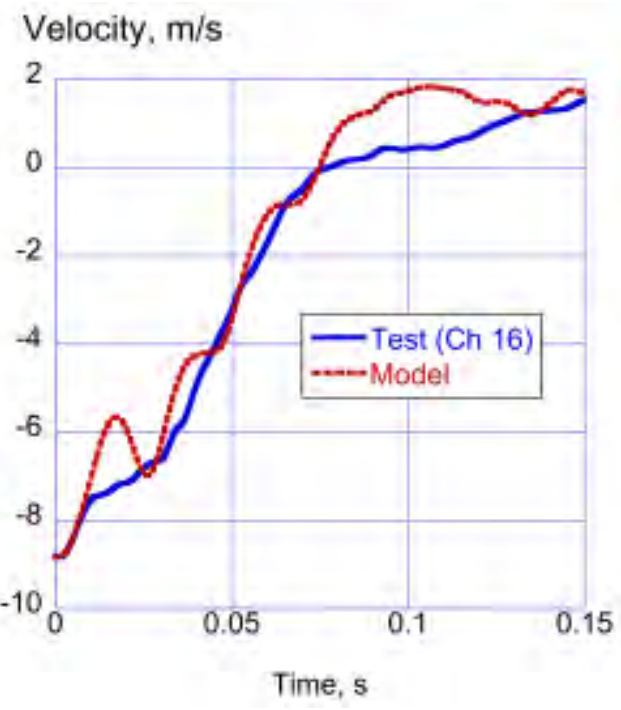

(b) Velocity responses.

Figure 10. Acceleration and velocity comparisons at the port window at FS 6805 .

The test/analysis comparisons of acceleration and velocity responses are shown in Figures 11 (a) and (b), respectively, for the port aisle location at FS 6805 (see Figure 5). The level of agreement between the test and model acceleration responses is not as good as seen previously. The model exhibits a peak of $40-\mathrm{g}$ at $0.04-\mathrm{s}$, and the test response exhibits a peak of 44-g at 0.056-s. Even the test and model velocity responses do not agree well. The test exhibits an initial negative velocity, which is not observed in the model response. Both curves cross zero velocity at different times and show different rebound responses.

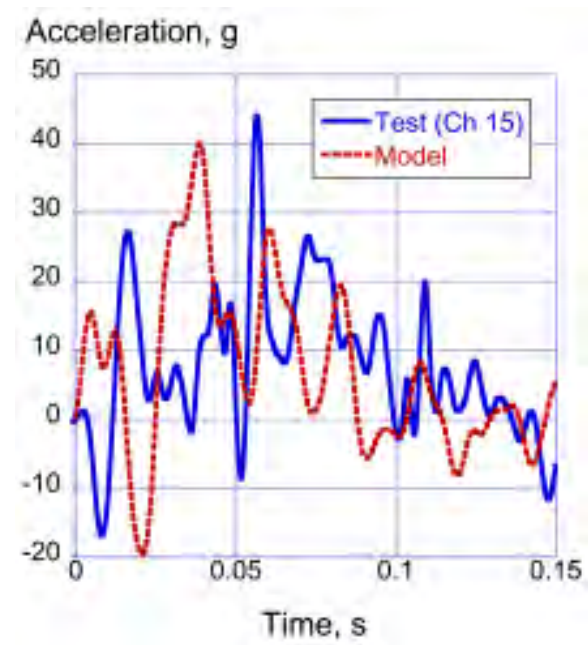

(a)Acceleration responses.

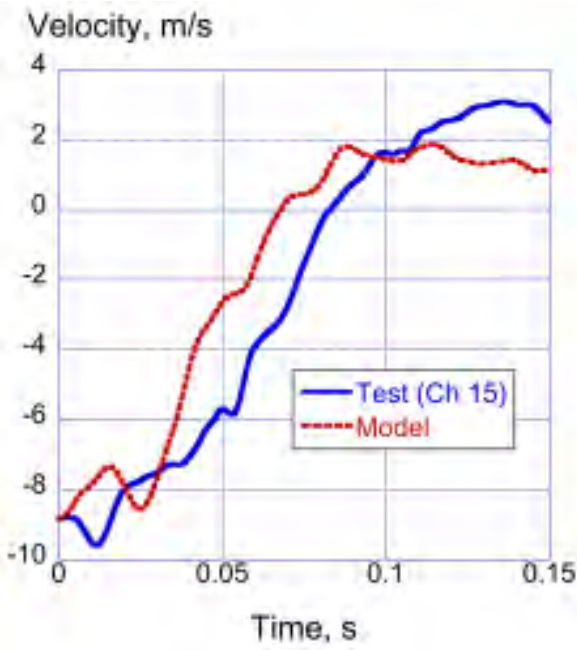

(b) Velocity responses.

Figure 11. Acceleration and velocity comparisons at the port aisle at FS 6805. 
The test/analysis comparisons of acceleration and velocity responses are shown in Figures 12 (a) and (b), respectively, for the starboard aisle location at FS 6805 (see Figure 5). At this location, the model acceleration response exhibits two peaks, one of 31.5-g and the second at 21-g. Once again, the test response contains many oscillations. The model crosses zero velocity sooner than the test velocity response. In addition, the model response removes velocity more quickly than the test and has a different rebound response than the test.

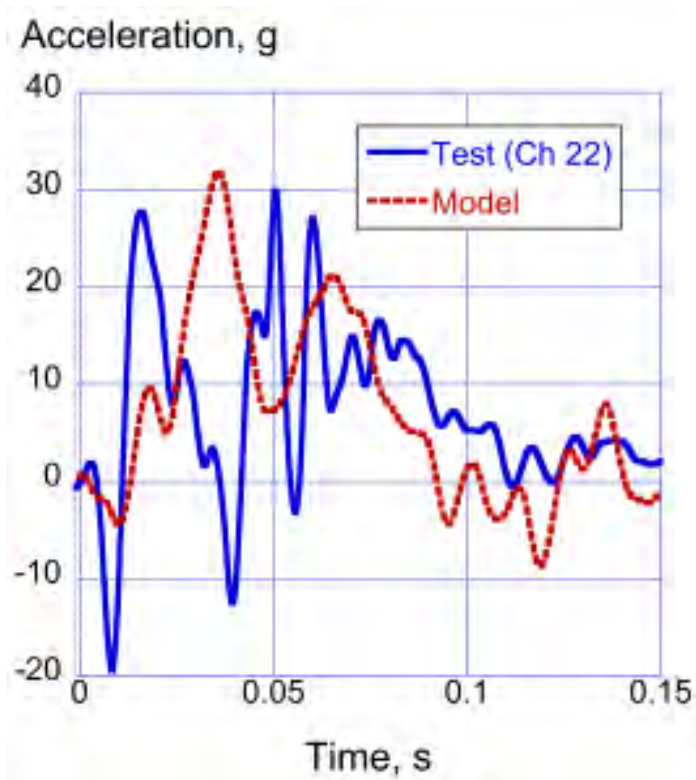

(a)Acceleration responses.

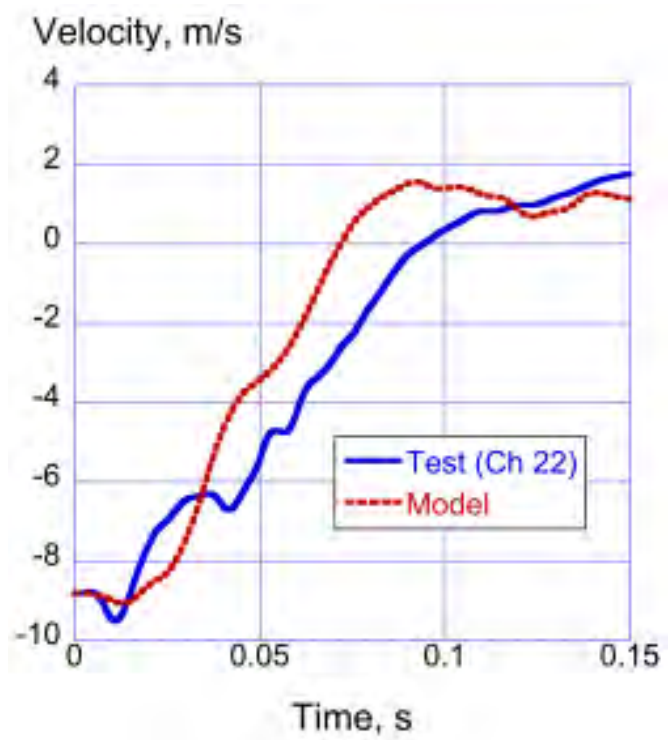

(b) Velocity responses.

Figure 12. Acceleration and velocity comparisons at the starboard aisle at FS 6805.

The test/analysis comparisons of acceleration and velocity responses are shown in Figures 13 (a) and (b), respectively, for the starboard window location at FS 6805 (see Figure 5). At this location, the model and test acceleration responses are similar, both responses exhibiting several peaks of similar magnitude. The velocity responses agree fairly well, with the model response removing velocity more quickly than the test and crossing zero sooner than the test. Both curves have similar rebound responses and magnitudes.

As a means of performing a more rigorous test/analysis comparison, the average acceleration was calculated for the experimental and analytical responses. The average acceleration was obtained by calculating the area under the acceleration curve from time zero to the end time of the pulse duration, and then dividing the area by the pulse duration. In general, the pulse duration was determined as the time of maximum rebound. These data are shown in Table 1, along with percentage differences between test and model data. All of the percentage differences are under $20 \%$, indicating a reasonable level of test/analysis agreement. Note that 5 of 7 data points are under $10 \%$. 


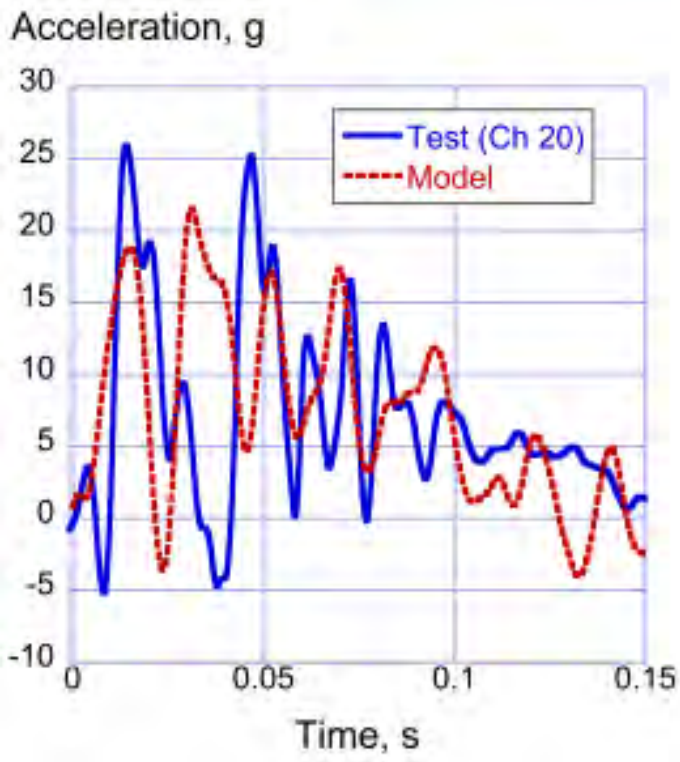

(a)Acceleration responses.

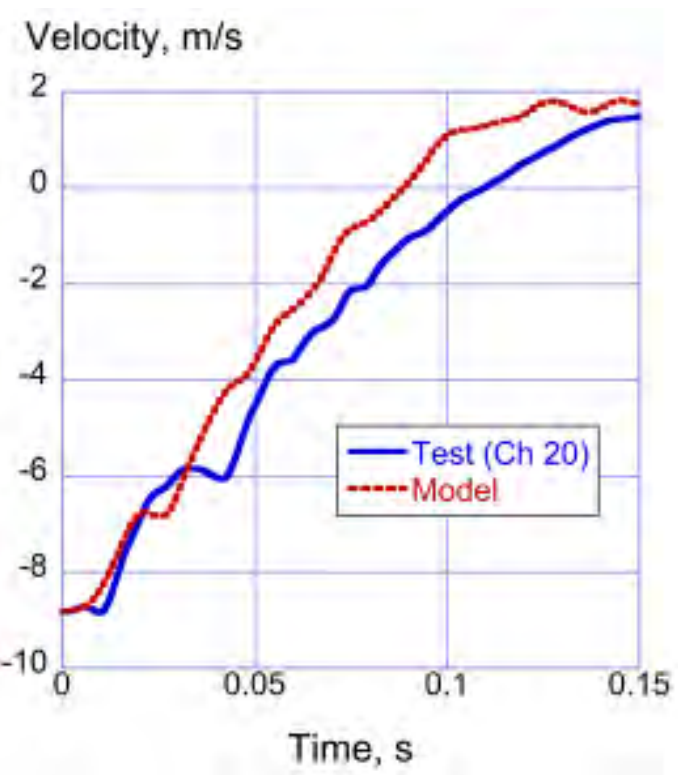

(b) Velocity responses.

Figure 13. Acceleration and velocity comparisons at the starboard window at FS 6805.

Table 1. Test-analysis comparison.

\begin{tabular}{|l|c|c|c|c|c|}
\hline Location & \multicolumn{2}{|c|}{ Pulse Duration, s } & \multicolumn{2}{c|}{$\begin{array}{c}\text { Average } \\
\text { Acceleration, g }\end{array}$} & $\begin{array}{c}\text { Percent } \\
\text { Difference, \% }\end{array}$ \\
\hline & Test & Model & Test & Model & \\
\hline Port Window at FS 5805 & 0.088 & 0.114 & 10.97 & 9.5 & 13.4 \\
\hline Port Aisle at FS 5805 & 0.1034 & 0.1034 & 10.47 & 10.53 & 0.57 \\
\hline Starboard Window at FS 5805 & 0.164 & 0.164 & 6.3 & 6.4 & 1.6 \\
\hline Port Window at FS 6805 & 0.134 & 0.134 & 7.48 & 7.59 & 1.5 \\
\hline Port Aisle at FS 6805 & 0.136 & 0.115 & 8.94 & 9.46 & 5.8 \\
\hline Starboard Aisle at FS 6805 & 0.119 & 0.119 & 8.38 & 8.36 & 0.24 \\
\hline Starboard Window at FS 6805 & 0.166 & 0.146 & 6.4 & 7.4 & 15.6 \\
\hline
\end{tabular}

\section{Comparison of Structural Deformation and Failure}

A post-test photograph of the test section is shown in Figures 14(a), in which the section has been completely unloaded, including removal of the hat racks, floor panels, and luggage. Discrete failure points at the floor level, as well as plastic deformation of the bottom centerline of the section, are evident. A picture of the model at $0.2-\mathrm{s}$, which is the end time of the simulation, is shown in Figure 14(b) without the luggage, hat racks, floor panels, and the soil impact surface. The model exhibits extensive failure of the floor support beams, especially in the central region of the floor. These failures are likely caused by flexure of the floor panels and pressure from the luggage. Alternatively, the test article has discrete failures of the floor support beams and seat tracks, as shown in Figure 15. Floor level failures include one complete separation of the seat tracks, and failures of the side-to-side floor support beams, as depicted in Figure 15. An impact sequence, taken from the high-speed video coverage, is shown in Figure 16. This figure depicts airframe deformation, as well as seat failures and 
occupant flailing. Note that both the model and the test article exhibit plastic deformation of the lower structure between the stanchions. Additional information regarding the F-28 section test can be found in Littell (2017).

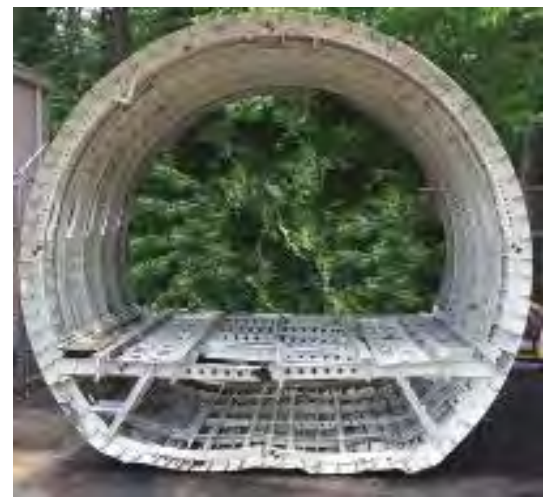

(a)Post-test photo.

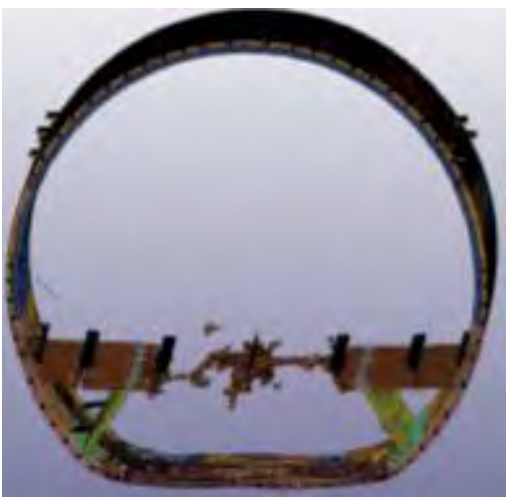

(b) Model photo at 0.2-s.

Figure 14. Post-test photo and model depiction at 0.2-s of the F-28 section.

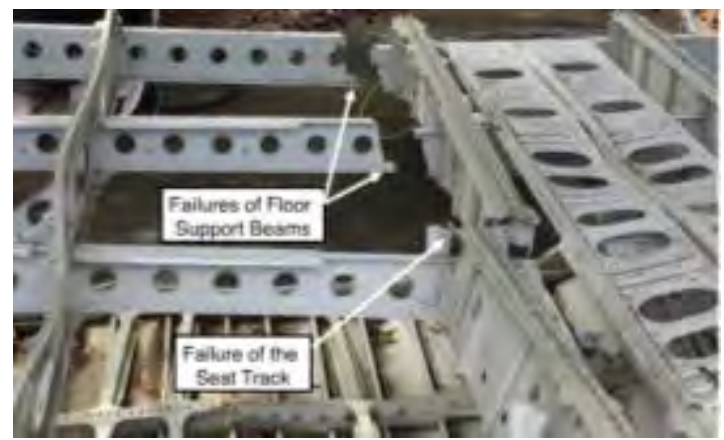

Figure 15. Photograph of floor-level failures.

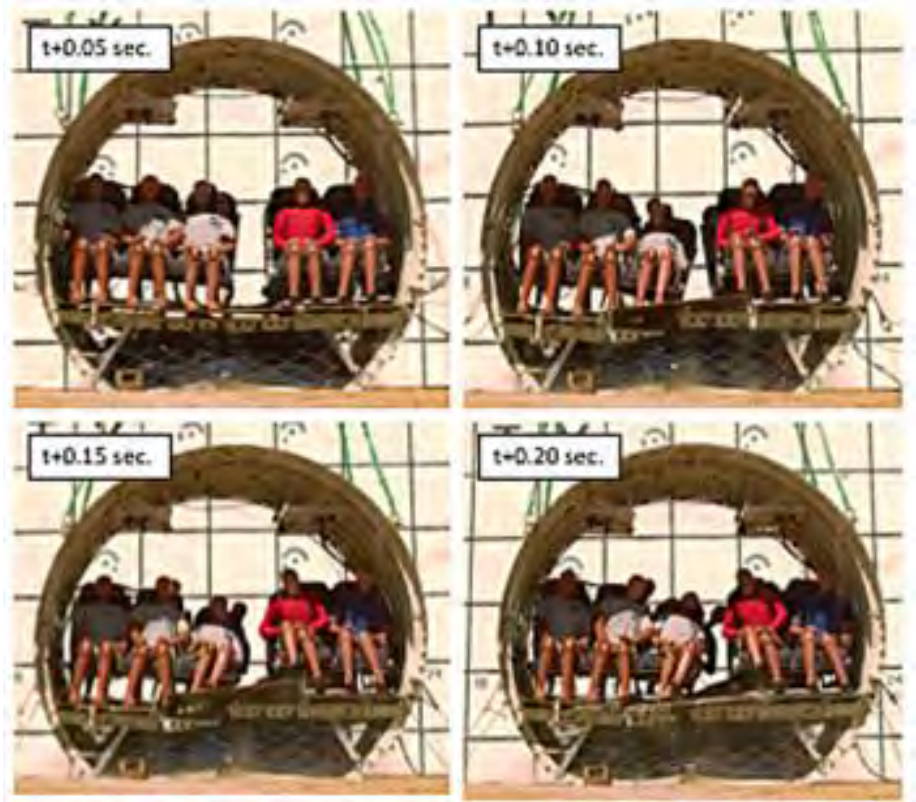

Figure 16. Impact sequence of the test. 
A sequence of model deformation is shown in Figure 17 for four time steps. The model shows excessive deformation of the luggage, indicating that the material properties may be inaccurate. However, some luggage deformation is evident in the test sequence, shown in Figure 16. The luggage does exert an upward force on the floor beams, which are bending due to seat track loading. It is interesting to note that the cargo door, which is located on the lower right side of the section when viewing the photos in Figure 16, causes asymmetry in the deformation pattern of the section. However, this effect is not seen in the model, likely due to the presence of the luggage. The cargo door and surrounding support structure were included in the model.

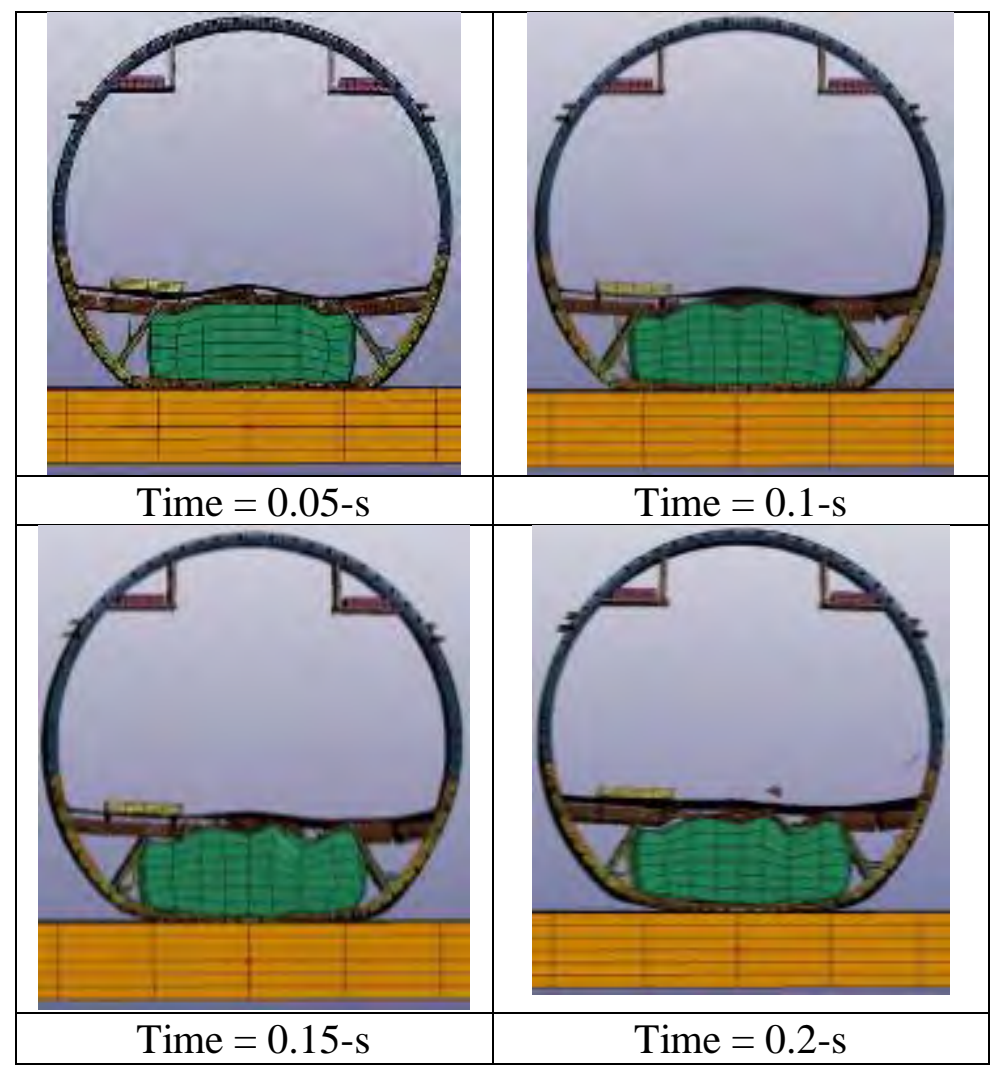

Figure 17. Model deformation sequence.

\section{DISCUSSION OF RESULTS}

This paper has presented the results of a finite element simulation of a F-28 forward fuselage section vertical drop test. The focus of the test/analysis comparisons was on seat track responses and structural deformations and failures. A comparison of average accelerations between the test and predicted responses indicated that all values are under $20 \%$, indicating a reasonable level of test/analysis agreement. Note that 5 of 7 data points are under $10 \%$. More exacting means of test-analysis comparison were not attempted in this paper. However, a new approach for quantifying test/analysis comparisons for model validation needs to be developed and utilized. 
For filtered acceleration time histories, the level of agreement can be determined by comparing the onset rate, magnitude, timing and overall shape of the acceleration response. Rarely will the analyst see "good" correlation between test and analysis in the sense of an absolute match for these parameters. In general, the level of correlation is deemed "good or reasonable" if these parameters are "in the ball park." Thus, the need to re-evaluate the current crash data analysis and correlation methodologies for use with detailed finite element model simulations has been identified. A project was initiated at NASA Langley to better quantify the accuracy of crash simulation results. The motivation for the project, as stated in Lyle (2002), was "to document modeling improvements, to evaluate design configurations analytically, and to enable certification or qualification by analysis." A conclusion of this reference was that continued work is needed to automate rigorous test-analysis correlation methodologies to improve and redefine the level of accuracy.

\section{CONCLUSIONS}

In March 2017, a vertical drop test of a 3.048-m (10-ft) section of a Fokker F-28 aircraft was conducted as a part of a joint NASA/FAA effort to investigate the performance of transport aircraft under realistic crash conditions. The section was configured with two rows of aircraft seats, in a triple-double configuration. A total of ten Anthropomorphic Test Devices (ATDs) were secured in the seats using standard seat belt restraints. The section was also configured with luggage in the cargo hold. The drop test was performed at the Landing and Impact Research facility located at NASA Langley Research Center. The measured impact velocity was $8.839-\mathrm{m} / \mathrm{s}$ (348-in/s) onto soil. A second objective was to assess the capabilities of finite element simulations to predict the test response. A finite element model was developed and executed in LS-DYNA ${ }^{\circledR}$. The model contained accurate representations of the airframe structure, the hat racks and hat rack masses, the floor and seat tracks, and the luggage in the cargo hold. Concentrated masses were used to represent the inertial properties of the seats, restraints, and ATD occupants. Analytical predictions of seat track acceleration and velocity responses were compared with measured data from the test. In addition, predicted structural deformations and failures of the airframe were compared with the test.

Major findings of this research are:

1. Analytical and experimental acceleration and velocity responses were plotted for seven seat track locations. These responses showed generally good agreement. However, even after filtering using a Society of Aerospace Engineering (SAE) Channel Filter Class (CFC) 60-Hz low-pass filter, the experimental data still contained many oscillations.

2. Average accelerations were determined for both the experimental and predicted responses and percentage differences were obtained. All of the values are under $20 \%$, indicating a reasonable level of test/analysis agreement. Note that 5 of 7 data points are under $10 \%$.

3. The simulation predicted excessive damage to the central floor region of the model, whereas the test article saw several discrete failures of the floor support 
beams and seat tracks. Both the test article and the model experienced plastic deformation of the lower fuselage structure between the stanchions.

\section{REFERENCES}

Fasanella E. L. and Jackson K. E. (2002). "Best Practices for Crash Modeling and Simulation," NASA TM-2002-211944, ARL-TR-2849.

Federal Register (2015). Federal Aviation Administration, Aviation Rulemaking Advisory Committee, Transport Airplane and Engine Issues, Vol. 80.

Hallquist J. O. (2006). "LS-DYNA Theory Manual," Livermore Software

Technology Company, Livermore, CA, March.

Hallquist J. O. (2006). “LS-DYNA Keyword User's Manual,” Volume II Material

Models, Version 971, Livermore Software Technology Company, Livermore, CA, August.

Hallquist J. O. (2006). “LS-DYNA Keyword User's Manual,” Volume I, Version 971, Livermore Software Technology Company, Livermore, CA, August.

Jackson K. E. and Fasanella E. L. (2002). "Crash Simulation of Vertical Drop Tests of Two Boeing 737 Fuselage Sections,” DOT/FAA/AR-02/62.

Jones L. E. (2002). "Overview of the NASA Systems Approach to Crashworthiness

Program," Proceedings of the American Helicopter Society 58th Annual Forum, Montreal Canada, June 11-13.

Littell J. D. (2010). "Large Field Photogrammetry Techniques in Aircraft and Spacecraft Impact Testing," Proceedings of the Society of Experimental Mechanics Annual Conference, Indianapolis, Indiana, June 7-10.

Littell J. D. (2016). "Experimental Photogrammetric Techniques used on Five FullScale Aircraft Crash Tests," NASA/TM-2016-219168.

Littell J. D. (2017). "Full Scale Drop Test of a Fokker F28 Forward Fuselage Section onto Soil," Aerospace Structural Impact Dynamics International Conference (ASIDI), Wichita, KS, October 17-19.

Lyle K. H., Bark, L. W., and Jackson, K. E. (2002) "Evaluation of Test/Analysis Correlation Methods for Crash Applications," Journal of the American Helicopter Society, Vol. 47, No. 4, pp. 219-232.

Lyle K. H., Stockwell A. E., and Hardy R. C. (2007). "Application of Probability Methods to Assess Airframe Crash Modeling Uncertainty," Journal of Aircraft, Vol. 44, No. 5, pp. 1568-1573.

Society of Automotive Engineering (1995). J211-1 Instrumentation for Impact Test Part 1-Electronic Instrumentation, Revision March, SAE International, 400 Commonwealth Drive, Warrendale, PA.

Stockwell A. E. (2003). "Fokker F28 Fuselage Section Drop Test Simulation and Test/Analysis Correlation," Report No. SDSR-07RCG-093003, Lockheed Martin Langley Program Office, Hampton, VA. 